\title{
Sobre algumas influências teóricas na construção de um tema: trabalho e classe trabalhadora na literatura recente
}

\section{Leonardo Mello e Silva*}

Resumo: O texto faz um balanço das análises sobre a emergência de um novo paradigma produtivo no Brasil e seus efeitos sobre o trabalho e a classe trabalhadora, tentando rastrear as linhas interpretativas mais recorrentes nessa literatura. Aborda em especial o impacto da teoria da regulação na sociologia do trabalho, por meio das noções de taylorismo e de fordismo. Como elemento distintivo, recupera o material da história social do trabalho no Brasil a fim de buscar um diálogo com as abordagens de cunho macroestrutural, confrontando teoria e história.

Palavras-chave: sociologia do trabalho no Brasil; história social do trabalho; classes trabalhadoras.

Abstract: This paper examines the most common and influential academic views about the emergence of a new model of productive organization in Brazil, as well as the presumed effects it brings to both work and the working classes. The main streams of that literature are shortly considered, drawing special emphasis upon the Theory of Regulation, and the concepts derived from it, such as taylorism and fordism. As a distinctive contribution, it appeals to a collection of recent work from Brazilian labour social historians as a tool to address the macro-structural account, and to bridge a dialogue between theory and history.

Keywords: sociology of work in Brazil; social labour history; working classes.

\section{I) INTRODUÇÃO}

O debate sobre o taylorismo e sua (suposta) crise deu o tom, nos últimos anos, na apreciação sobre a reorganização do trabalho e novas formas de organização das empresas ${ }^{1}$. Esse debate foi muito difundido na Europa e convergiu com duas outras fontes intelectuais, complementares e reciprocamente reforçadoras: uma vertente crítica da divisão do trabalho, com tintura por vezes autonomista, por vezes foulcaultiana (baseada nos dispositivos de disciplinarização), e uma outra vertente - marxista - ancorada nos estudos

\footnotetext{
* Professor doutor do Departamento de Sociologia da USP.

${ }^{1}$ Para um balanço dessa literatura, consultar T. Nichols e H. Beynon (Eds.) The fordism of Ford and modern management: Fordism and Post-Fordism. Two Vols. Cheltenham: Edward Elgar, 2006.
} 
acadêmicos sobre o processo de trabalho animados pelo sotaque anglo-saxão da The Conference of Socialist Economists.

No Brasil, tal debate encontrou uma conjuntura algo diferente dos países industriais do centro do capitalismo: não um esgotamento do padrão fordista de produção e consumo, mas talvez a sua maturação. Os analistas do movimento sindical não se cansaram de apontar para a décalage do ciclo de lutas operárias entre o Norte capitalista e o Sul periférico - no caso, nós: enquanto no primeiro o refluxo dos conflitos de classe aplainava o terreno para a reação neoliberal que viria em seguida, aqui o novo sindicalismo e o surgimento do Partido dos Trabalhadores (PT) insuflavam esperanças utópicas surpreendentemente contra a corrente. Aqui como lá, o modo de se trabalhar, com cadências impostas pela economia do tempo taylorista e fordista, tinha seus adversários no mundo do trabalho, inclusive os sindicatos. Muitas das reivindicações de metalúrgicos do $A B C$ paulista da época, por exemplo, detiveram-se nesse quesito (intensificação do ritmo, controle hierárquico, limitação e desqualificação do saber profissional etc.). Mas havia também diferenças importantes. Tratava-se de duas "temporalidades" que é preciso entender a partir de uma definição ampla do fordismo como um modo de regulação, e não apenas como uma forma de organizar o trabalho. Seguindo nessa linha, vamos nos deparar com a caracterização, para países como o nosso, com um tipo particular, o "fordismo periférico", em vez do modelo hegemônico que marcou os "Trinta Gloriosos" (período que vai, grosso modo, do segundo pós-guerra até meados dos anos 1970). Pontos em comum (daí se falar genericamente em "fordismo"), e também pontos de descontinuidade (daí "periférico"). Mas aí, então, é preciso contar a estória inteira.

\section{II) O APORTE DA ESCOLA DA REGULAÇÃO}

O taylorismo e o fordismo são conceitos-chave para a Escola da Regulação. Sua influência na sociologia do trabalho é indireta, já que se trata de uma formulação intelectual originalmente mais afinada com a literatura econômica. No entanto, não deixa de ser desafiadora, na medida em que propõe uma explicação de conjunto para determinadas mudanças de padrão (ou "modo") de desenvolvimento. 
Em linhas gerais, essas mudanças estão relacionadas com a passagem de um regime de acumulação extensivo para um regime de acumulação intensivo no capitalismo. Para explicar a estabilização dessa última configuração, o papel do taylorismo na organização do trabalho é de fundamental importância, pois ele permite ao mesmo tempo racionalizar a produção, introduzindo elementos de previsibilidade e de aumento da produtividade e eficiência, e fixar um modo de remuneração associado aos resultados alcançados em termos da rentabilidade advinda pela aplicação exatamente daqueles métodos racionalizadores. Transformações essenciais transcorridas nas relações industriais têm lugar a partir da aplicação do taylorismo: a hierarquia das qualificações operárias sofre um rearranjo, em decorrência da desqualificação de alguns ofícios e da presença cada vez mais marcante de técnicos com prerrogativas de controle da aplicação dos métodos de trabalho definidos nos escritórios de planejamento da produção, assim como novas atribuições aos contramestres. O embate entre dois tipos de saberes - um mais empírico e transmitido internamente entre as gerações de trabalhadores, e outro com caráter mais formal e forjado por meio de operações abstratas de cálculo e projeções de determinadas condições ideais - experimenta um confronto acerbo quando das primeiras tentativas de introdução do taylorismo, estabilizando-se depois, entre outras razões, pela conjuntura de crise e desemprego, a qual termina por enfraquecer a oposição ao modelo.

Também o Estado passa a ter uma presença mais determinante nas relações, antes concebidas como essencialmente privadas, entre capital e trabalho: um estilo de capitalismo de bem-estar derivado de políticas paternalistas de empresas e direcionadas a sua força de trabalho é substituído por normas gerais que devem ser seguidas por causa de sua superioridade técnica: assim, a racionalização da produção exigida pelo "esforço de guerra" no período entre as duas guerras mundiais, por exemplo, minou esforços particulares de capitalistas que visavam ao controle total dos aspectos da manutenção e reprodução de "seus" trabalhadores. Os efeitos da concorrência, claro, devem ser mencionados como fator de difusão dos métodos mais eficientes. Mas a intervenção da vontade estatal, ao menos nesse episódio histórico fulcral, serve de advertência para uma mudança mais geral que vai se observar com a maior clarividência depois: o nexo cada vez mais estreito entre o investimento privado e as condições (fiscais e sociais) que o agente público vai possibilitar e assegurar. 
De todas as transformações, contudo, a mais decisiva para o sucesso do taylorismo, e mais tarde do fordismo, é a institucionalização da formação dos salários com base nos ganhos de produtividade. São os contratos coletivos e as negociações por ramo de atividade que irão sacramentar esse formato, com consequências econômicas e políticas: arrefecimento do ímpeto revolucionário das lutas de classe e deslocamento do conflito trabalhista para a arena das agências estatais ou jurídicas. Por outro lado, os efeitos mais diretos (e também os mais conhecidos) da aplicação do taylorismo sobre o trabalho operário são a parcelização, a mecanização, o salário incitativo e a cronometragem - todos eles, sobretudo os três primeiros, associados à divisão do trabalho (e à sua crítica) -, devendo computar-se também os efeitos indiretos, relacionados à "mudança de atitudes" dentro e fora do trabalho. Como se pode notar, esses elementos característicos do taylorismo são facilmente aproximáveis de outras correntes explicativas e de inspirações teóricas que se debruçaram sobre o mesmo objeto.

Outros efeitos da racionalização taylorista não diretamente ligados à organização do trabalho poderiam ser mencionados: o relacionamento da empresa com os outros segmentos da produção (fornecedores), além da própria comercialização (com a redução de modelos ofertados) e a concepção dos produtos, ou a estandardização das ferramentas e instrumentos, conduzindo a uma padronização dos equipamentos técnicos. Com respeito à organização da empresa, deve-se notar a maior integração ou unificação de funções antes dispersas (como vendas e projetos), implicando maior controle e previsão, e servindo-se ademais de instrumentos estatísticos de acompanhamento e mensuração, além da criação de novas divisões e departamentos internos. Por todos esses motivos combinados, pode-se entender melhor a afirmação de um autor como Robert Boyer de que o taylorismo possui um caráter "estruturante"

Essa rápida digressão sobre o significado da aplicação do esquema de interpretação regulacionista convoca imediatamente a pergunta sobre a sua pertinência em casos de países como o Brasil. Passando pelas fases de substituição de importações (1), de abertura ao capital estrangeiro no modelo associado-dependente (2), de modernização autoritária do "milagre" (3), e, depois, de ajuste ao neoliberalismo (4), a periodização do desenvolvimento

\footnotetext{
${ }^{2}$ BOYER, Robert. "Présentation" à seção "Le Taylorisme hier". In: MONTMOLLIN, Maurice de; PASTRE, Olivier. Le Taylorisme. Paris: La Découverte, 1984, p. 35-47.
} 
pode oferecer um confronto interessante com aquele modelo explicativo do capitalismo, dado que ele permite mobilizar uma tentativa de integração entre sistema-mundo e periferias, dessa vez utilizando-se de certos conceitos-chave. O taylorismo e o fordismo são, sem dúvida, conceitos-chave. São também aqueles que estabelecem uma conexão mais direta com as realidades do trabalho e da classe trabalhadora, tema deste breve ensaio. Desse ângulo, a caracterização do regime de acumulação desde 1930 como o início de uma trajetória de construção de uma base endógena de desenvolvimento capitalista tem ressonâncias com o fordismo central (a relativa autonomização dos setores econômicos em relação a um polo dinâmico externo, seja como comprador de matérias-primas, seja como ofertante de bens manufaturados, gerando cadeias produtivas auto-sustentadas) e afasta uma identificação desses espaços como sendo de plataformas de exportação de produtos industrializados (para o centro ou para outras periferias) associados à vantagem comparativa da superexploração da força de trabalho.

Tal é a hipótese original de Lipietz ${ }^{3}$, com isso chamando a atenção para o fato de que a taylorização e os baixos salários, no nosso caso, são a variante de uma trajetória de acumulação intensiva, conforme se observou nos países centrais. Por isso não se justifica a caracterização de espaços subalternos - como o nosso - na divisão internacional do trabalho enquanto um todo indiferenciado. Seria exatamente esse tipo de operação intelectual reducionista o que permite eventualmente aproximar a simples maquiladora - para tomar um exemplo latino-americano bem típico - do esforço de implantação de "indústrias industrializantes" (o que pressupõe o acoplamento de produção e consumo de bens duráveis), embora o traço de união entre ambas seja, de fato, o de descarregar sobre o trabalho (quer na falta de regulamentação do seu uso, quer nas dificuldades burocráticocorporativas de contratação livre do tipo "afogados em leis"^) a responsabilidade sobre a sustentação de ambas as configurações, seja por meio de compressão salarial, de erosão inflacionária ou simplesmente através da repressão às reivindicações. O taylorismo, naquele marco conceitual, é mais do que uma modalidade de divisão do trabalho opressiva e exploradora. Embora, na superfície, haja traços em comum nas duas configurações

\footnotetext{
${ }^{3}$ LIPIETZ, Alain. Miragens e milagres. Problemas da industrialização no Terceiro Mundo. São Paulo: Nobel, 1988, p. 87-133.

${ }^{4}$ Para essa idéia, veja-se o trabalho de FRENCH, John. Afogados em leis. São Paulo: Perseu Abramo, 2001.
} 
caracterizadas acima (i.e., maquiladoras e "indústrias industrializantes"), elas são contudo bem particulares.

Ora, se o trabalho, em sentido amplo, está na base dessas diferenciações (da periferia com relação ao centro; da periferia com relação à periferia), então parece nada menos do que coerente, a partir de agora, debruçar-se mais detidamente sobre esse aspecto (em lugar de outros, também legítimos, do modo de regulação: o financiamento, a dívida, o progresso técnico etc., e mesmo a política das classes dominantes e o Estado). Como observa o autor ${ }^{5}$, são as relações de classe em cada situação nacional particular que explicam a estabilização de determinada configuração, e não o contrário, à maneira funcionalista, isto é, da arquitetura do sistema-mundo, ou da divisão internacional do trabalho, derivar-se-ia a "lógica" da periferia. Esse approach crítico confere à história e à sociologia um papel não negligenciável para a explicação das diferenças nos modos de regulação.

\section{III) AS TRAJETÓRIAS NACIONAIS}

Nos EUA, o taylorismo significou a substituição do operário de ofício, ou profissional, pelo operário desqualificado, em geral imigrante e sem experiência de organização coletiva. Muda assim a composição de classe da força de trabalho industrial, na passagem do século dezenove para o século vinte. Encarado como obstáculo à racionalização do trabalho por causa do conhecimento empírico sobre o processo, o uso das ferramentas, e todos os "segredos" associados à interação entre o elemento subjetivo e o elemento objetivo na produção, o trabalhador qualificado de ofício é o alvo da investida tayloriana, o que dá lugar a uma luta intensa que vai se estender durante as primeiras décadas do século passado.

No Brasil, uma força de trabalho industrial em boa parte também imigrante, mas uma industrialização ainda longe da escala e do repertório da americana, vai no entanto encontrar entre os industriais paulistas dos anos vinte e trinta uma recepção bastante entusiasmada dos ideais tayloristas ${ }^{6}$. Faltam, contudo, algumas condições básicas para a

\footnotetext{
${ }^{5}$ LIPIETZ, A. op. cit.

${ }^{6}$ Consultar a propósito ANTONACCI, M. Vitória da Razão (?): o IDORT e a sociedade paulista. Rio de Janeiro: Marco Zero, 1992; WEINSTEIN, B. A (re)formação da classe trabalhadora no Brasil: 1920-1964. São Paulo:
} 
reprodução do fenômeno americano: na verdade, o tipo de indústrias e de processos de trabalho que requeressem aquele tipo médio de operário-massa, desqualificado e abundante. Esbarrando em um problema basicamente de oferta do tipo de emprego industrial que justificasse um investimento em estudos de tempos e movimentos e uma capacitação de gerências que substituísse o poder patriarcal-autoritário no trato com os empregados de boa parte das indústrias então prevalecentes, o taylorismo nativo vai permanecer antes como um apelo ou verniz modernizador a fornecer às elites uma tintura teórica poderosa em sua campanha pela racionalização do modo de vida da sociedade. Mas seu efeito prático é limitado. O taylorismo brasileiro, precoce no discurso, como se viu, vai se dissolver em um ideário racionalizador que, embora algumas vezes tomando ares de necessidade e mesmo de "missão", não vai atingir a vida das fábricas diretamente. Vai alimentar, no entanto, o estoque de argumentos de uma intelligentsia americanista que se aninhará, depois, nos aparelhos de Estado. Esse é a tese de trabalhos como os de Nilton $\operatorname{Vargas}^{7}$ e, em certa medida, de Werneck Vianna ${ }^{8}$.

O tipo de trabalho requerido pelas indústrias de então, bem como o tipo ou perfil do trabalhador adequado, vai aparecer no discurso empresarial, além das clássicas alusões à preguiça e à tendência "natural" à vagabundagem, como solicitando uma agilidade manual que, não fosse a carência de uma formação moral adequada, colocaria os nossos operários no mesmo nível, ou até mais bem posicionados, do que os do Primeiro Mundo. É exatamente esse ponto - a necessidade de educação e formação da força de trabalho industrial que alie, por exemplo, hábitos de asseio e higiene com o acesso a um mínimo de comunicação letrada - que parece ser o nó da questão. Ele, na verdade, concerne a um problema real - do qual, aliás, vai se ocupar mais tarde o SENAI e o SESI -, mas que, no fundo, depende de uma verdadeira mudança de padrão no tipo de industrialização vigente até então: de uma industrialização que tinha como principal influxo a importação, para outro, que se assenta na construção das bases internas da acumulação de capital: a famosa "endogenização" das condições de produção e reprodução do capital. Mas, como a fórmula

Cortez/USF, 2000; VARGAS, N. Origens e difusão do taylorismo no Brasil. Ciências Sociais Hoje 1985. São Paulo: Cortez/Anpocs, 1984.

${ }^{7}$ VARGAS, N. op. cit.

${ }^{8}$ VIANNA, L. Werneck. Liberalismo e sindicato no Brasil. Rio de Janeiro: Paz e Terra, 1976. 
mesmo adianta, a reprodução do capital depende da reprodução da força de trabalho em bases também "endógenas".

Isso significa assegurar, para os empresários, uma oferta relativamente estável de braços para pôr em marcha os processos produtivos, uma "função" classicamente preenchida pelo Estado, assim como seria uma "função" deste último promover, através de políticas creditícia, fiscal e diretamente produtiva (naqueles setores em que o investimento privado nacional não estivesse em condições de fazê-lo), as bases do desenvolvimento capitalista. Consoante com essas preocupações, a "nacionalização" da força de trabalho não deve ser medida pela Lei dos 2/3 de Getúlio Vargas, mas, sobretudo, pelo fluxo migratório interno em direção aos centros urbanos, o que vai gerar preocupações quanto à qualificação e ao "ajustamento" do trabalhador ao modo de vida industrial. Haveria que se estudar aqui dois processos simultâneos: primeiro, como se deu a transmissão do saber profissional de uma geração (Primeira República) para outra, nos setores tradicionais do parque industrial; segundo, como se criou, enfim, uma classe trabalhadora para os setores novos e mais dinâmicos. Assim como a passagem de um setor de atividade a outro não é uma criação ex nihilo, mas uma transmutação do capital - uma metalúrgica que inicia a partir da "importação" de um departamento de manutenção mecânica ou de ferramentaria oriundo de um setor completamente diverso ${ }^{9}$-, também a passagem dos saberes que vão constituir em seguida as qualificações dos operários, formalmente identificadas, é trazida de experiências pretéritas, cujo ponto de origem pode estar na fase anterior.

A criação de uma classe trabalhadora para os setores "novos", isto é, as atividades industriais que deveriam promover a substituição de importações, constitui o ponto de mutação entre uma estratégia taylorista e outra propriamente fordista. Porque agora a ação do empresariado e do Estado (o primeiro chamando ao trabalho o segundo) terá de se preocupar com a formação de uma classe trabalhadora no seu aspecto tanto produtivo quanto reprodutivo. É nesse sentido que o ideário fordista é mais apropriado do que o taylorista para caracterizar o momento da industrialização varguista: porque o primeiro se

9 Da mesma maneira que a unidade têxtil do Grupo Matarazzo começou suas atividades por causa da necessidade de fabricar os sacos para o armazenamento dos grãos trazidos da Argentina, no final do século XIX. Veja-se a propósito deste exemplo o trabalho de MARTINS, José de Souza. Conde Matarazzo: o empresário e a empresa. 2a․ Ed., São Paulo: Hucitec, 1976, p. 31. 
preocupa com algo que ao segundo não interessava (por razões doutrinárias ademais bastante coerentes): a vida privada dos seus operários - toda a preocupação moralizadora se encaixa aqui ${ }^{10}$. A produção do IDORT (Instituto de Organização Racional do Trabalho), um discurso no diapasão da racionalização, é pródiga desses achados.

Esse parece ser o nexo da distinção conceitual entre taylorismo e fordismo: enquanto o primeiro foi o artífice da organização "científica" do trabalho e fundou os ganhos de produtividade a partir da norma de produção derivada dos princípios que ele mesmo compilou (divisão do trabalho, estudos de tempos e movimentos, concentração da decisão na gerência etc.), o segundo inventou uma verdadeira "relação salarial", o que quer dizer que a partir da generalização do sistema de disciplina e incentivo aplicado em sua fábrica de automóveis foi possível estabilizar uma norma social de consumo que alimentou o circuito interno de reprodução do próprio sistema, debelando uma crise (a concorrência feroz de capitais baseada na guerra de preços) e inaugurando uma era de regulação (o papel contracíclico do Estado e o pacto produtivista entre trabalho e capital). Assim, uma caracterização histórica geral, estilizada, deve ser vista com muita cautela, claro, quando deslocada para outros contextos. No entanto, há elementos de continuidade entre as trajetórias de desenvolvimento do Norte (centro) e do Sul (periferia). Por isso, a pertinência dessa arquitetura conceitual não parece de todo descabida.

No desejo de libertar-se de constrangimentos tecnológicos e financeiros, as economias do Sul, em determinado momento de suas histórias nacionais, fizeram opções bastante próximas do fordismo "clássico", limitadas contudo pelas condições de dependência de uma nova divisão do trabalho emergente do pós-guerra. Visto do ângulo da constituição de uma relação salarial mais próxima do desenho protecionista que o (primeiro) período Vargas tinha esboçado para a economia brasileira, o modelo fordista parece bastante plausível.

Porém, em termos genéricos, o fordismo não dispensa o taylorismo. Ele o contém. Assim, se para o operário do século XIX a luta na fábrica era uma luta ao mesmo tempo contra a desqualificação e contra a dilapidação de sua força física, vamos encontrar essa

\footnotetext{
${ }^{10}$ A preocupação com a vida privada dos operários (no estilo vila operária) não seria, a rigor, um traço taylorista, mas ainda paternalista e tradicional. O que não impede, contudo, que os processos produtivos possam ser modernos e racionalizados.
} 
mesma "pauta", recorrente, em contextos posteriores, tanto nas indústrias (e serviços) dos países desenvolvidos quanto nos não completamente desenvolvidos. No Brasil, a resistência operária à organização do processo de trabalho capitalista na época do "milagre" (19681975) expressou-se por meio de reivindicações muito próximas àquela "pauta". São elas: 1) queixas contra as hierarquias ou chefias que exercem um papel repressivo ou autoritário; 2) contra os ritmos de produção; 3) contra os procedimentos de gestão dos "recursos humanos", por meio - como em alguns casos concretos - de regulamentos internos muito rígidos (poder disciplinador); 4) contra o arrocho salarial. Tais práticas patronais estão associadas, em um nível mais amplo do que o quadro nacional, ao taylorismo-fordismo exceto a última. A elas devem ser acrescentadas as condições macroestruturais ou institucionais, além daquelas mais ligadas à chamada "política do chão de fábrica", como eram naquele momento; 5) o sindicato atrelado ao Estado; 6) a Lei de Greve; e 7) a política salarial do governo. Para isso - ou com esse espírito - podem ser elencadas, já naquela conjuntura, algumas campanhas empresariais de integração dos trabalhadores à "casa". Iniciativas desse tipo em geral vêm de grandes empresas, que podem gastar tempo e dinheiro com essas campanhas ${ }^{11}$. Seu conteúdo pretende mais do que apenas obter "consentimento": visa sobretudo a obter sugestões dos operários envolvidos diretamente na produção, como é o caso dos Círculos de Controle da Qualidade (CCQs). As políticas "participativas" direcionadas à força de trabalho são, claro, uma resposta à movimentação operária do final dos anos 1970 e incluem já (meados dos anos 1980) alguns traços dos "novos paradigmas" que vão se espalhar mais amplamente um pouco mais tarde: são eles o sistema de rodízio ou "polivalência" e os grupos de trabalho que, no entanto, se assentam em postos de trabalho definidos individualizadamente, à maneira taylorista.

Já em janeiro de 1982 a Tribuna Metalúrgica (do Sindicato dos Metalúrgicos de São Bernardo e Diadema) chamava a atenção criticamente para alguns resultados dessas políticas: o operário não era mais qualificado, ao contrário, ele passava a ser percebido muito mais como prescindível, como "pau para toda a obra", como se o rodízio fosse o atestado de sua condição de "peão" ao invés de um "profissional", além do efeito da

\footnotetext{
${ }^{11}$ Elas podem tomar vários nomes: "Juntos para o futuro", da Volks em 1982, por exemplo, num momento de grande tensão com a implantação das Comissões de Fábrica. Veja-se MARONI, Amnéris. Fábrica: espaço de poder. Desvios, n² 2, p. 30-52, 1983.
} 
competição interpares, com cada companheiro tornando-se o "patrão" do colega. Nesse período, um forte sentimento de pertencimento ao grupo operário, feito de orgulho (a "dignidade") e de limitação de um espaço social de reconhecimento, tornava plausível e coerente uma representação em termos de "nós" e "eles". Naquele período, o Sindicato dos Metalúrgicos do $A B C$ toma uma posição resolutamente contrária tanto às campanhas de integração das empresas, quanto aos CCQs e à extração de sugestões por parte dos operários. É uma postura diferente do Sindicato dos Metalúrgicos de SP, arquirrival do primeiro em termos de concepções do sindicalismo, o qual topa uma espécie de barganha com o patronato: o reconhecimento das comissões de fábrica pela aceitação dos CCQs uma postura do "toma lá dá cá" que vai, dez anos depois, caracterizar as iniciativas da corrente cutista concorrente (os acordos sobre redução da jornada com manutenção do emprego, a partir de 1996, por exemplo).

Outro aspecto que merece ser relembrado no ciclo de lutas operárias do $A B C$ é a maneira como a vanguarda organizativa da classe encarava a negociação direta com o patronato: como um avanço, um dado positivo do movimento, mesmo com o sindicato do lado deles, como aliado. Isso significa que a compreensão da negociação direta entre operários e patrões não era vista como uma alternativa tática por causa da indisponibilidade do sindicato, mas como uma ação deliberada que deveria ser levada avante, como uma forma de educação política.

Tudo parecia indicar, naquele momento, a permanência do taylorismo no Brasil, embora misturado com políticas e estratégias gerenciais que, nos países do Norte, pareciam indicar a sua "superação". Mas essa visão ainda soa insuficiente para caracterizar o modo de regulação de uma economia periférica, porém "em desenvolvimento", como é o caso da brasileira.

\section{ONDE TUDO COMEÇOU}

No Brasil, vamos encontrar um taylorismo precoce ainda nos anos 1920, em São Paulo, e que se encarnou em instituições como o IDORT, a Escola Politécnica, a FIESP, a Escola de Sociologia e Política, entre outras. Mas vamos encontrá-lo com mais dificuldade 
quando se trata de aplicá-lo, em sua pureza doutrinal, nas próprias fábricas, local por excelência de sua experimentação. Segundo Nilton Vargas (1985), trata-se da disjunção entre "princípios" e "técnicas", fazendo dos primeiros um discurso sem lugar, tendo em vista que as condições sociais e econômicas não possibilitavam ainda a reprodução de uma força de trabalho endógena, o que só vai ocorrer a partir de 1930, com o fim do pacto excludente da Primeira República. No entanto, pontualmente, a "gerência científica" já estava presente desde os anos 1910, graças ao pioneirismo de Roberto Simonsen na Companhia Construtora de Santos ${ }^{12}$. É no setor de construção civil, portanto, que são primeiramente testados os ensinamentos do engenheiro norte-americano, tanto em seus aspectos doutrinários (reconhecimento dos operários como seres dotados de interesse), quanto em seus aspectos práticos (remuneração; bônus; criação de um Departamento Técnico para o estudo "científico" desses assuntos; centralização das negociações fora da influência "política" leia-se: sindical) ${ }^{13}$.

Estudos sobre o IDORT ${ }^{14}$ e o sistema SESI-SENAI ${ }^{15}$ detêm-se mais na mentalidade racionalizadora dessas instituições, deixando ainda no escuro a aplicação desses métodos nas empresas, bem como os problemas e limitações advindos daí, isto é, a questão do embate do taylorismo com a força de trabalho e as condições técnicas e sociais de organização fabril em uma situação particular. Seria o que poderíamos chamar de um estudo histórico sobre o processo de trabalho.

Indicações esparsas extraídas da literatura historiográfica, aqui e ali, oferecem algumas pistas, mas sobretudo para as condições de trabalho, não apontando, contudo, para estudos científicos orientados ao aumento da produtividade. Tudo leva a crer, aliás, que essa era uma preocupação dispensável: mais importante parecia ser a utilização extensiva da força de trabalho. À "fome de braços" correspondia o dispêndio de uma massa de trabalho vivo desqualificada e sem necessidade de formação profissional prévia ${ }^{16}$. 0 enorme salto de produtividade advindo com a incorporação de tecnologia de ponta aos processos produtivos

\footnotetext{
${ }^{12}$ SILVA, Fernando Teixeira da. Operários sem patrões. Os trabalhadores da cidade de Santos no entreguerras. Campinas: Ed. da Unicamp, 2003, p. 65-102.

13 Ibidem, p. 100-101.

${ }^{14}$ ANTONACCI, M. A. op. cit.

${ }^{15}$ WEINSTEIN, B. op. cit.

${ }^{16}$ NEGRO, Antonio L. Linhas de montagem: o industrialismo nacional-desenvolvimentista e a sindicalização dos trabalhadores. São Paulo: Boitempo, 2004, p. 189.
} 
nos anos de industrialização acelerada de JK foi possibilitado exatamente pelo baixo custo da força de trabalho de então ${ }^{17}$. Nessa hipótese, o taylorismo nacional alimentou-se, tal como seu congênere americano, de uma mão de obra desqualificada, porém sem qualquer contrapartida do tipo de uma norma salarial indexada à produtividade, para o que o papel de negociação dos sindicatos seria fundamental. Ao contrário, a relação salário real $\mathrm{x}$ produtividade no Brasil dos anos 1950 parece ter-se construído a expensas do primeiro termo, tendo contribuído para isso a fraca influência política da classe trabalhadora ${ }^{18}$ nas instituições dedicadas à regulação macroeconômica.

Fraca influência nas instituições decisivas de regulação não significa, bem entendido, débil presença mobilizada nos lances do jogo político e algo dramáticos da conjuntura do trabalhismo. Significa, vista de um outro ângulo, pôr o dedo naquilo que seria o ponto de fuga de uma moldura fordista para as relações entre as classes no período: a negociação coletiva autônoma em relação ao Estado. Nesse tópico precisamente, um sindicalismo de tipo americanista teria sido mais eficaz, embora, como fica claro hoje a partir do trabalho de Negro (2004), nos seus primórdios esse sindicalismo fosse deliberadamente orientado para desestabilizar a "esquerdização", observada pelos setores conservadores, dos governos com apoio de sindicatos ligados à CGT. Em suma, ficou-se apenas com o taylorismo, sem os benefícios do fordismo. Sem a incorporação da parcela assalariada ao circuito de reprodução do capital, o modo de consumo fordista restou capenga, restrito às classes médias (renda e acesso ao crédito). À medida que o custo de reprodução da força de trabalho começa a se "urbanizar", nas palavras de Oliveira (1972), isto é, começa a depender de uma reprodução interna à própria sociedade urbano-industrial, na forma mercadoria, a renda assalariada teria de acompanhá-lo, a fim de evitar desequilíbrios entre o salário real e o referido custo de reprodução. Tal não ocorreu, o que explica a superexploração a que estavam expostos os operários no período, mesmo com os aumentos nominais de salários ${ }^{19}$.

Outras indicações completam o desenho pintado acima. Em 1965, Negro ${ }^{20}$ chama a atenção para as queixas na Volkswagen de São Bernardo: impossibilidade de recusa de horas extras, existência de vapores e gases no ambiente de trabalho, falta de liberdade para ir ao

\footnotetext{
${ }^{17}$ OLIVEIRA, Francisco de. A economia brasileira: crítica à razão dualista. Petrópolis: Vozes/Cebrap, 1972 , p. 50.

${ }^{18}$ OLIVEIRA, F. de. op. cit., p. 54-55.

${ }^{19}$ Ibidem, p. 57-58.

${ }^{20}$ NEGRO, A. L. op. cit., p. 265.
} 
banheiro, rotatividade com sentido de disciplinamento e substituição por um contingente mais dócil. Recuando no tempo, do lado do enquadramento formal das funções produtivas, há uma remissão a iniciativas do IDORT, por volta do Estado Novo, de estabelecer um programa de "verticalização das qualificações" ou de "detalhamento das especializações", mas esse tópico é apenas citado, não desenvolvido ${ }^{21}$, o que seria muito interessante em termos da construção de um "sistema de classificações" das profissões - iniciativa que acabou sendo levada a cabo pelo Ministério do Trabalho. A palavra do IDORT parece servir como inspiração para a organização do trabalho dentro das empresas, como linha geral dentro dos princípios racionalizadores, mas o taylorismo realmente existente era uma prerrogativa privada e sobre a qual os documentos não são muito abundantes. Registre-se apenas a sugestão de uma correlação entre intensificação do ritmo de trabalho e acidentes na indústria têxtil ${ }^{22}$.

É muito impreciso derivar o discurso (das associações de classe) da prática (da organização fabril). Mesmo assim, é digna de nota a preocupação com os ideários da organização científica do trabalho pelos nossos industriais em situação tecnológica e produtiva tão distante da produção em massa industrial que era levada a cabo nos EUA por engenheiros como Taylor, empresários como Ford, e especialistas do trabalho como Elton Mayo. Os obstáculos a uma implantação coerente do taylorismo estavam, assim, muito mais nas condições na disseminação dos pré-requisitos a uma acumulação de tipo intensiva, incluindo o mercado de trabalho e a reprodução do assalariamento, do que na iniciativa voluntarista do empresariado paulista da Primeira Republica. Mas, seguindo nesse sentido o aggiornamento muito típico entre burguesia industrial e pensamento autoritário no Brasil, o ideário do IDORT e da racionalização vai estar presente também no Estado Novo e no corporativismo, sem provocar grande mal-estar ideológico ${ }^{23}$.

No entanto, não eram apenas bons salários o que contava. Uma certa "proteção" representada pela grande empresa, no sentido de um escudo mais sólido contra a demissão do empregado - relativamente à empresa menor, sem uma estrutura organizacional

\footnotetext{
${ }^{21}$ ANTONACCI, M. A. op. cit., p. 229.

22 Ibidem, p. 232-233.

23 Esse tópico é muito bem trabalhado por Luiz Werneck Vianna. op. cit.
} 
desenvolvida -, também fazia a diferença. ${ }^{24} \mathrm{O}$ padrão de comportamento estritamente mercantil do operário que fazia a sua escolha com base apenas em critérios de racionalidade econômica via salário - ideal veiculado pela ideologia tayloriana, mesmo que ingênua, em seu individualismo empreendedor - não parece, nem de longe, gozar de uma difusão efetiva entre a população trabalhadora (exceto, talvez, para os qualificados, como os ferramenteiros). Assim, um certo paternalismo "moderno" podia vigorar (anos 1950 e 1960 na indústria automobilística) na ausência de uma contratação sindical que oferecesse apoio e segurança de emprego, mitigando o temor constante da dispensa unilateral por parte do patrão. Este último, segundo Negro, vendia caro "o ingresso do trabalhador na firma 'moderna', inserindo-o numa relação de reciprocidade que, a um só tempo, colocava-o em dívida com a 'companhia' e Ihe oferecia a conquista da dignidade" ${ }^{25}$. Assim pode ser reproduzido tanto o discurso surrado da "cordialidade" do trabalhador, quanto reforçadas as estratégias integradoras da empresa: o familialismo, a religião, a moralidade, a propriedade (a casa própria).

Uma situação de extrema carência dos contingentes recém-chegados à cidade, além da penúria material entre os que aqui já estavam - dada a contração salarial já mencionada -, juntamente com a dificuldade de traduzir lutas por direitos em uma ação contratualista efetiva (o ponto de fuga do fordismo, referido mais acima) explicam a permanência de um padrão de paternalismo de empresa (ela dá tudo: restaurante, ônibus, até salário - veja-se essa passagem extraída de Negro: "o cidadão chegava aqui, do interior ... principalmente do Nordeste, e nunca tinha visto o salário-mínimo ..."26), embora, por sua vez, ela cobrasse simbolicamente essa dívida. Dada a composição social da força de trabalho, os primeiros "peões" da indústria tendiam a encarar os benefícios então encontrados como um grande avanço em relação às condições de vida: “... Quando viemos para Santo André, sentimos melhoria de $100 \%$. Porque lá [refere-se a seu lugar de origem] não se via dinheiro (...)"27. No entanto, tais "benesses" não cancelavam a percepção nítida da usura representada pelo trabalho industrial, nem a falta de liberdade que este significava: "Uma vez na fábrica R. (primeiro emprego que teve em São Caetano), depois de aqui chegar há dez anos, fiquei

\footnotetext{
${ }^{24}$ NEGRO, A. L. op. cit., p. 309.

${ }^{25}$ Negro, A. L. op. cit., p. 309.

${ }^{26}$ Ibidem, p. 187.

${ }^{27}$ Ibidem, ibidem.
} 
olhando aquelas paredes... e disse para o chefe: faz minha saída, vou embora. Ele disse que não. Não quer dar, eu saio, falei, não estamos na escravidão! Ele fez a saída, falando: este povo do interior é uma coisa. Saí, respirei aquele ar puro (...)"28.

Mas, como se fez referência, esse não era um movimento de mão única. Fortes ${ }^{29}$, analisando o caso das Indústrias Renner no Rio Grande do Sul, entre os anos 1930 e 1940, atesta a contrapartida de lealdade exigida pelo patrão pelos serviços sociais então bastante avançados para os padrões da época: a existência de médicos, dentista, farmácia, restaurante, seguro de vida, cooperativas de consumo e de crédito, além de creche e de subsídios à esposa do trabalhador, com valores proporcionalmente crescentes à medida que a prole aumentava - dispositivos aparentemente contraditórios, mas bastante coerentes com a mentalidade familialista (homem provedor da família) e a expectativa de manutenção do emprego feminino apenas até a primeira maternidade - compensam a disciplina fabril exigida no respeito ao "princípio natural da hierarquia", onde, ademais, diferenças étnicas (pertencimento à comunidade teuto-brasileira e domínio da língua alemã) deixavam muito claro os lugares de uns e outros. O lado moralizador do fordismo marca sua presença, neste último caso justificado ideologicamente por um "capitalismo social" ${ }^{30}$ que vê a si mesmo como superando a filantropia empresarial (o amparo ao trabalhador justifica-se, segundo A. J. Renner, não porque seu patrão se tenha condoído de sua sorte, mas porque é um direito que lhe é reconhecido) e, por isso mesmo, não incompatível com a legislação trabalhista varguista.

Aqui tocamos em um tópico delicado.

Um grande mal-entendido que opõe uma interpretação "sociológica" à interpretação da história social diz respeito à avaliação que os trabalhadores faziam de seu próprio trabalho. Se a história social oferece a chance de reconstruir uma linha de causalidades muito mais fina e especificamente ancorada no caso concreto, a sociologia se permite generalizações baseadas em grandes tendências evolutivas ou em padrões de comportamento. Essa é a forma aparente como as fricções entre essas disciplinas - na verdade, uma dessas friç̧ões - vem à luz. Afinal, os operários brasileiros da indústria

\footnotetext{
${ }^{28}$ LOPES, Juarez R. B. Sociedade industrial no Brasil. São Paulo: Difel, 1964, p. 45.

${ }^{29}$ FORTES, Alexandre. Nós do Quarto Distrito. A classe trabalhadora porto-alegrense e a Era Vargas. Caxias do Sul: Educs/Garamond, 2004, p. 202-207.

${ }^{30}$ Ibidem, p. 204.
} 
automotiva do início dos anos 1960, berço da industrialização acelerada e do fordismo possível por essas bandas, trocavam o atrativo do salário - o "ordenado" na fala do operário entrevistado por Leôncio Martins Rodrigues ${ }^{31}$, ponto ademais discutido por Negro $^{32}$ - pelo desinvestimento total na atividade laborativa a que estavam confinados em um processo de trabalho repetitivo e massacrante? As respostas a essa pergunta, do ponto de vista da sociologia, da ergonomia e da psicodinâmica do trabalho, têm sido negativas: não, os operários - mesmo sob as linhas tayloristas - jamais deixam de mobilizar a inteligência, o saber-fazer, os macetes e os ardis, tanto práticos quanto subjetivos, para manter o próprio ritmo e assim controlar minimamente sua relação com o processo objetificante das máquinas, dos instrumentos e da organização a que estão confrontados. Mas a percepção do salário como o único elo entre o operário e o trabalho é também o atestado de que os "semiqualificados" e "braçais" já fazem parte de um contingente da força de trabalho que, expropriada das condições próprias de reprodução, vagam na cidade como consumidores de bens mercantilizados, além de produtores. Essa percepção é coerente, ademais, com a figura da classe sob uma relação salarial fordista. O grande problema da interpretação sociológica no Brasil foi inferir desse estado social do coletivo dos trabalhadores da grande indústria uma orientação para fora do mundo fabril, bem como da promessa (ideal) contida nele de mobilidade e integração no modo de vida urbano, dado que o "ordenado" podia ser o acesso não para o aprofundamento da subsunção real, mas, ao contrário, para a ativação de tendências centrífugas, isto é, de "volta" para a pequena propriedade rural. Além disso, mesmo sem uma atitude tipicamente orientada para a valorização do trabalho como ofício, nada prescrevia a ação daquele contingente como necessariamente hostil a uma organização coletiva dentro das fábricas por conta dos problemas oriundos da organização do trabalho ali existente. Também nesse caso, há coerência com a figura da classe na relação salarial fordista, desta vez em sua crise. O mérito da interpretação historiográfica sobre a classe trabalhadora foi chamar a atenção para dois tipos de generalização abusiva: o primeiro, aquele que estabelecia um trajeto unívoco que ia das atitudes à desmobilização de uma ação coletiva de classe (a história posterior do novo sindicalismo negou isso); o segundo, aquele que deduzia desta última a recepção entusiasmada dos apelos populistas.

\footnotetext{
${ }^{31}$ RODRIGUES, Leôncio Martins. Industrialização e atitudes operárias. São Paulo: Brasiliense, 1970, p. 63.

${ }^{32}$ NEGRO, A. L. op. cit., p. 154-155.
} 
Não é, portanto, sem razão que a inspiração thompsoniana sobre a classe social como fazerse contínuo caiu muito bem no tipo de interpretação crítica devida à história social, pois ela foi capaz de demonstrar os pontos de contato e de continuidade de ação coletiva onde uma interpretação evolucionista e esquemática via apenas ruptura e inapetência política.

Ao contrário, a ênfase na classe encarada do ponto de vista de suas escolhas e dos dilemas concretos com os quais se defrontava permitiu construir um outro tipo de coerência, de tal maneira a traçar uma linha de continuidade entre o passado e o presente; entre, por exemplo, as demandas sobre condições de trabalho, sobre participação e sobre democracia no local de trabalho etc. O operário fordista de $1963^{33}$, preocupado mais com o salário do que com o trabalho, é uma figura sociologicamente plausível; daí não decorre, contudo, a demissão de sua identidade de classe, como muitas vezes se atribui.

O caráter "de massa" do operariado fabril entre os anos quarenta e sessenta aparece em vários estudos dedicados à industrialização desse período e sua relação com o trabalho. Ele é bem retratado por Ramalho ${ }^{34}$, que para os meados dos anos 1940 expõe a concepção que os planejadores tinham da necessidade de formação, discriminando três tipos de operários: o "completo" (cuja contribuição para o processo de trabalho não passa de 20\%) e, no outro pólo, os "auxiliares", ficando no meio o "simples operário de máquina", dedicado a operações que não requeriam "especial tirocínio", mas sim muita habilidade manual. Negro lembra, para um período um pouco posterior, que as fábricas absorviam "gente cujas ocupações pouco tinham a ver com as máquinas" e "aprendizes viravam profissionais da noite para o dia" ${ }^{35}$.

No ramo das indústrias químicas não era diferente: afirma Fontes, sobre uma das empresas mais importantes do setor, também nos anos 1950, que "não era necessário um grande número de operários qualificados na escola [refere-se à escola do SENAI, implantada em 1943 em São Miguel Paulista, região da cidade de São Paulo onde se situa a fábrica] para 'tocar' a empresa. Seu processo de produção prescindia de trabalho qualificado em diversos setores da companhia. Alguns trabalhadores especializados somados a um número maior dos que 'aprenderam na prática' e uma grande massa operária pouco ou nada instruída (e

\footnotetext{
33 Ano da realização da pesquisa de Leôncio Martins Rodrigues. op. cit.

${ }^{34}$ RAMALHO, José Ricardo. Estado-Patrão e luta operária: o caso FNM. Rio de Janeiro: Paz e Terra, 1989, p. 47.

${ }^{35}$ NEGRO, A. L. op. cit., p. 149.
} 
com altos índices de rotatividade) eram suficientes para garantir a produção" ${ }^{36}$. Ainda segundo o autor, somente $20 \%$ dos contratados possuíam alguma experiência anterior no setor industrial ${ }^{37}$. A grande maioria era de migrantes do Nordeste. A transmissão do saber operário não era mais processada pelo mestre de ofício ou pelo trabalhador com maior qualificação. Tudo leva a crer que as máquinas - elas mesmas cristalização de trabalho morto - estabeleciam um novo patamar de aprendizado que fazia prescindir o acúmulo ciosamente construído a partir das qualificações ligadas à produção com caráter mais artesanal. O "ofício" com que alguns designavam a importância de "ter um ofício" era

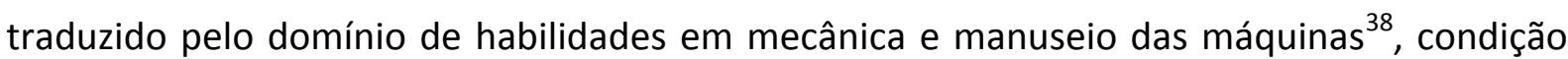
suficiente para assegurar estabilidade em uma grande firma. Nesse sentido, talvez possamos interpretar as queixas primevas do IDORT quanto à falta de qualificação do trabalhador brasileiro muito mais como uma inadequação à socialização no modo de vida urbanoindustrial do que propriamente como a falta de alguma qualificação técnica específica; afinal, a maior parte desses operários eram mesmo "peões". Mas essa não é uma afirmação inteiramente apropriada, porque se encontra, aqui e ali, uma demanda de força de trabalho qualificada, em um patamar que pressupõe alguma formação técnica mais elevada ${ }^{39}$, em clara distinção em relação ao pessoal estritamente de execução, a "peãozada". Na relação salarial realmente existente do período desenvolvimentista, uma divisão no interior do próprio trabalho assalariado industrial parecia instituir uma segmentação entre um contingente em relação ao qual valia a pena investir em formação, e um outro para o qual o destino manifesto era cumprir o vaticínio taylorista do "operário tipo boi", reconhecido na linguagem popular como o "pau para toda a obra". Se a socialização no modo de vida urbano-industrial e no ethos fabril, com a carga de disciplina e autocontrole que ele implica, vale indistintamente para os dois grupos, é para o primeiro que se voltam as atenções pragmáticas e imediatistas das empresas. Até porque, dando certo, é esse grupo que será o espelho no qual vai mirar-se boa parte dos contingentes do segundo grupo.

\footnotetext{
${ }^{36}$ FONTES, Paulo. Trabalhadores e cidadãos. Nitroquímica: a Fábrica e as lutas operárias nos anos 50. São Paulo: Annablume, 1997, p. 85.

${ }^{37}$ FONTES, P. op. cit., p. 84.

${ }^{38}$ NEGRO, A. L. op. cit., p. 149-50.

${ }^{39}$ FONTES, P. op. cit., p. 92.
} 
De todo o modo, com ou sem a aplicação consequente dos métodos de organização científica do trabalho nas fábricas entre 1930 - marco de uma industrialização orientada para dentro - e 1970, o fato é que a prescindibilidade da qualificação (mínima que fosse, com algum traço de experiência fabril anterior, não se confundindo, portanto, com o trabalhador "de ofício"), aliada à oferta de emprego industrial em função da implantação da industrialização de bens de consumo duráveis no País, criou a imagem de um taylorismo associado à voraz absorção de braços do tipo "pau para toda a obra", alimentando por tabela a representação popular de que aquela fora a "época de ouro" dos empregos nas fábricas de um país que se industrializava, deixando de lado progressivamente seu passado de uma modernidade acanhada.

Cumpre agora perseguir uma outra vertente interpretativa que também influiu poderosamente na construção de nosso tema de estudos, entre os anos de 1970 e 1990.

\section{IV) A VERTENTE "AUTONOMISTA"}

A relação controle versus resistência no processo de trabalho era pensada segundo o esquema seguinte: a razão para a substituição do homem pela máquina (o que, nesse caso, se referia ao progresso técnico, embora pudesse, como sabemos, envolver também a introdução do trabalho de mulheres e crianças) não foi, como atribui o argumento econômico, a busca por maior produtividade, e sim a resistência operária ao sistema de fábrica, expressa em atos como quebra de máquinas, greves e outras manifestações. "Politizar" a fábrica significava, assim, enfatizar o elemento ativo e voluntário das classes, em detrimento de determinações saídas do discurso lógico da Economia Política. O controle aparece envolto em um campo discursivo que esconde sua normatividade sob o manto da naturalidade: a lei, a economia política e a ciência ${ }^{40}$. A resistência, por meio de lutas de classe ou de movimentos sociais, demonstra exatamente o caráter conflituoso daquela realidade, a da sociedade do trabalho. Móveis e valores levantados pelos atores coletivos ganham assim grande importância analítica porque seus argumentos não são apenas uma

40 DE DECCA, Edgard S. A Ciência da Produção: fábrica despolitizada. Revista Brasileira de História. n. 6, p. 47-79. Rio de Janeiro: Marco Zero, 1984. 
espécie de "peça" pregada contra seus verdadeiros interesses, que eles, por uma razão ou outra e à falta de maior reflexão, não conseguem identificar. Ao contrário, levam-nos muito a sério.

Tome-se o exemplo do ideal de justiça. Se é certo que existe historicamente uma "justiça" que é a cristalização do domínio de uma classe (a "justiça burguesa", por exemplo), não é menos verdade que os atores coletivos vão definindo, de acordo com sua experiência, certos ideais de justiça ou do que é moralmente aceitável. Isso vale para os grupos sociais em disputa, para as classes, embora com maior pertinência para aqueles grupos dominados que veem uma distância crescente entre as promessas do ideal e a realidade efetiva. Um caso sempre muito lembrado é o que contrapõe o sentido fortemente moralizante que possuía o trabalho para os artesãos ou trabalhadores de ofício das primícias da Revolução Industrial e o discurso contratualista sobre os "homens livres para vender sua força de trabalho". Da mesma maneira, mas vindo do polo oposto, o sentido despudoradamente tutelar e disciplinador das preocupações da classe dominante europeia do século dezenove em relação aos mores, hábitos e vida familiar das "classes perigosas" nega a divisão estrita (ideal) entre as esferas do público e do privado. Essas representações, de um lado e de outro, contribuem, numa linguagem bourdieusiana, para estruturar a estrutura, que, no entanto, já está posta (a lei e ordem liberais da separação das esferas). É esta última que permite enquadrar a iniciativa dos burgueses como tutelar, filantrópica e caritativa, na mesma medida que a iniciativa operária como uma luta pela cidadania e pelo reconhecimento como sujeito de direitos.

É possível também, ainda dentro do molde europeu de industrialização e formação das classes modernas, enxergar os lugares do lazer e da folga do trabalho dos operários (jornal, cabaré, feiras, festas, pubs, cafés, bilhares, jogos etc.) como um elemento do espaço público burguês, dos homens-livres proprietários e pais de família, lugar igualmente da livre circulação de mercadorias. Ora, tal espaço público é também o espaço da politização, da formação da opinião pública - por isso, quando se busca higienizá-lo, é igualmente da supressão e repressão da circulação de opiniões e ideias que se trata.

Outro elemento da industrialização que essa corrente põe em relevo é o sistema de fábrica como um sistema de confinamento. Nesse sentido, um dos reforços importantes para que o confinamento pudesse funcionar era o sistema de salários: o pagamento por 
peça em lugar do salário-mínimo ajudava a criar um laço de dependência do trabalhador em relação ao ofertante do emprego.

A sociedade disciplinar do trabalho encontra eco em outras iniciativas disciplinares fora do trabalho. Assim, o papel do componente de gênero é muito importante para essa vertente. Mas a periodização das formas de controle e poder que ela sugere, em geral, não corresponde exatamente à periodização dos modos de regulação, tal como esboçado nas seções anteriores. Trata-se de duas abordagens com filiações teóricas e ênfases algo distintas, embora possam convergir em algum momento da argumentação - como no caso do significado da divisão do trabalho sob o taylorismo.

É exatamente no tópico do taylorismo que a contribuição da vertente autonomista encontra o elo mais explícito com as análises em termos de modo de regulação, desde que a entendamos como a tradução da problemática italiana do obreirismo, e não da maneira vaga e inespecífica, como reação aos mecanismos disciplinares na produção. 0 obreirismo ${ }^{41}$ consiste numa corrente intelectual saída do ambiente político militante da esquerda italiana dos anos 1960, estendendo-se como influência até o início dos anos 1970. Foi o caldo de cultura para o surgimento de vários grupos políticos que deram expressão à chamada "Esquerda Extraparlamentar". No entanto, para os propósitos deste ensaio, o que importa é a localização ali de uma reflexão bastante profícua em termos do capitalismo do pós-guerra na Europa, em sua relação com o ciclo de lutas e de mobilizações operárias ligadas aos partidos de massa. Tal reflexão, registrada na importante publicação Quarderni Rossi e animada por Ranieri Panzieri ${ }^{42}$, terminou por estimular o que ficou conhecido como o "retorno a Marx", o que na prática significava uma revalorização das leituras sobre a maisvalia relativa na obra $O$ Capital, isto é, sobre a relação entre o processo de trabalho e o processo de valorização.

A fortuna crítica do obreirismo acusou o momento de reestruturação produtiva já em seu nascedouro, em meados dos anos 1970, e dali uma importante elaboração tomou forma no debate que opunha o "operário massa" ao "operário social": o primeiro, a figura coletiva

\footnotetext{
${ }^{41}$ Tradução aproximada do termo italiano 'operaismo'.

${ }^{42}$ Importantes contribuições deste autor - Sobre el uso capitalista de las maquinas (ed. em castelhano, La División Capitalista del Trabajo. Córdoba: Cuadernos de Pasado y Presente 32, 1972) e Mais-Valia e Planejamento: notas sobre a leitura de 'O Capital' (ed. em português, Processo de trabalho e estratégias de classe. Rio de Janeiro: Zahar, 1982) - foram decisivas para constituir o campo dos estudos do processo de trabalho, cuja ponta de lança institucional foi a Conference of Socialist Economists, em 1976.
} 
típica da força de trabalho fabril dos processos de trabalho tayloristas; o segundo, a figura coletiva que traduzia a extensão daqueles princípios para a esfera da circulação de mercadorias, e já não mais da produção industrial strictu sensu, o que incluía os trabalhadores de serviços, os subcontratados, precários, desempregados ou atípicos. 0 debate em torno do obreirismo ${ }^{43}$ expõe não só o destino que se estava entrevendo, nos círculos intelectuais militantes, para a crise do movimento operário, como também a identificação das mudanças de composição - demográfica e social - de classe então em curso.

Enquanto o "operário massa" era o sujeito das formas de produção em massa do pacto fordista, o "operário social" prometia um outro nível de intervenção, o que demandava mudanças culturais, de formas de acesso e de lutas dessa nova população que, no entanto, não deixava de ser, mediatamente, operária. No Brasil, o apelo (apenas intelectual, bem entendido) do obreirismo se fez notar no momento de irrupção do ciclo de greves operárias do final dos anos 1970. O "novo" movimento operário parecia conter elementos de semelhança com a geração de jovens operários italianos oriundos do Sul subdesenvolvido e orientados para o norte industrial, sem a socialização "heroica" da geração precedente, bem como propensa a fazer funcionar o processo produtivo e a confrontar nele o "controle operário". Mas havia também elementos promissores do "operário social" nessa versão brasileira, na medida em que as greves de trabalhadores se espraiavam para outros setores sociais (bancários, construção civil, jornalistas, professores etc.) de extração profissional diversificada, todos, entretanto, abrigados sob a identificação de "companheiros". A discussão (italiana) acerca da passagem do "operário massa" ao "operário social" ganhava, no caso brasileiro, um contorno interessante pela possibilidade da atualização de duas figuras produtivas em uma mesma etapa histórica. Mais uma vez está-se diante de um problema de periodização, tal como no caso do taylorismo e do fordismo.

Por todas essas razões, talvez seja útil desagregar os componentes internos da "vertente autonomista". O mesmo vale, aliás, também para os dois grandes conjuntos de influências analisados neste ensaio. Com isso, tem-se em vista aproveitar as sugestões que

\footnotetext{
${ }^{43}$ O debate está descrito em NEGRI, Toni. Del obrero-masa al obrero social. Barcelona: Anagrama, 1980.
} 
essas vertentes, tomadas cada uma dentro de sua coerência interna, podem oferecer. A riqueza de seu emprego dependerá do grau de conexão que consigam estabelecer com a tradição consagrada sobre a formação do trabalho e da classe trabalhadora na sociedade brasileira, nem que seja para, a partir dessa conexão, tecer a sua crítica.

\section{V) BALANÇO}

O texto teve como propósito cruzar algumas influências, testando os pontos de contato entre elas, a partir de evidências extraídas de contribuições recentes da história social do trabalho no Brasil. Centrou-se basicamente em torno da discussão sobre o taylorismo e o fordismo, e mais especificamente sobre o quesito da qualificação do trabalho e seu significado para uma interpretação de conjunto dos períodos da industrialização brasileira. O diálogo com as etnografias que se detêm em aspectos mais profundos desse panorama muito generalizante seria o passo seguinte.

Subjacente ao propósito de examinar a pertinência das vertentes regulacionista e autonomista para as explicações acerca da formação da classe trabalhadora no Brasil está a tentativa de abordar velhas questões com novos instrumentos de compreensão, a fim de tentar enquadrá-los de um ponto de vista menos parcial. Concretamente, o exame deveria responder a perguntas do tipo: que classe social é essa que migra para os grandes centros urbanos sob o empuxe da industrialização acelerada, no Brasil dos anos do desenvolvimentismo? Que classe social é essa que fica nos grandes centros, e que classe social é essa que volta, quando pode, para o interior, de onde partiu? Quais as forças que atraem e repelem esses contingentes? Os mesmos indivíduos que fazem parte de um conjunto podem também fazer parte do outro conjunto? Se é assim, qual a força heurística da noção de "classe trabalhadora industrial"? A classe trabalhadora seria composta tanto de elementos do primeiro grupo (os que ficam) quanto do segundo grupo (os que voltam)? Nesse sentido, poderíamos falar de uma "falta de caráter" da classe trabalhadora brasileira? Ou, antes de constituir-se em uma característica particular macunaímica, não seria essa, ao invés, uma característica partilhada por outras classes trabalhadoras em outros contextos nacionais de formação? 
Como explicar, por exemplo, que as expectativas de ganhar mais e subir de cargo na empresa ${ }^{44}$, e portanto de elevação do padrão de consumo, sejam um traço de "saída" da categoria social operária no Brasil, quando essas mesmas expectativas foram compatíveis exatamente com a consolidação da identidade operária nos países que tiveram uma experiência próxima do fordismo?

Qual é a perdurabilidade de uma reivindicação por dignidade no trabalho, de recusa do poder e do controle heterônomo sobre o trabalho, em um contexto em que o comportamento instrumental e individualizante do trabalhador é encontrado tanto em uma ideologia racionalista-taylorista, quanto em um cálculo raso e de curto prazo do tipo "abrir um negócio próprio" e sair o mais rápido possível do sistema de fábrica? Este último comportamento desemboca no fordismo? Como discernir em que "lugares" estão essas ideias?

Espero ter tornado claro que o tratamento dessas (antigas) questões é o pano de fundo para o breve apanhado realizado neste texto sobre algumas vertentes explicativas no interior da literatura recente sobre trabalho e classe trabalhadora no Brasil.

Recebido em 20/10/2009

Aprovado para publicação em 08/04/2010

${ }^{44}$ RODRIGUES, L. M. op. cit., p. 37-38. 